\title{
Development of a KDP crystal growth system based on TRM and characterization of the grown crystals
}

\author{
S. Javidi, H. Faripour, M. Esmaeil Nia, K.F. Sepehri, N. Ali Akbari \\ Crystal Growth Lab., Metallurgy Group, Material Research School, NSTRI, \\ P.O. Box 14395-836, Tehran, Iran
}

\begin{abstract}
A solution growth system has been built based on temperature reduction method [1]. A few KDP crystals were grown by the system up to $160 \times 40 \times 38 \mathrm{~mm}$ dimensions. Spectrophotometer transmission spectra from (100) planes of the grown crystals show about $86 \%$ transmission in the visible region. XRD analysis, laser damage threshold, and microhardness of the crystals were determined. The etching behavior of surface features of grown KDP single crystals was studied in different etchants.
\end{abstract}

Keywords: growth from solution, KDP crystal, nonlinear optical materials.

Manuscript received 14.04.08; accepted for publication 20.06.08; published online 15.09.08.

\section{Introduction}

KDP crystals are among the first non-linear crystals to be used for the non-linear frequency conversion. The important characteristics of this crystal are wide transparency [2], high efficiency of frequency conversion, and high damage threshold against high power lasers [34]. The advantage of the growth of KDP crystals in larger dimensions than other non-linear crystals [5] has made it to be used in a wide range of applications, especially in laser fusion [6-9]. The growth technique for production of commercial crystals is based on gradual temperature reduction. In this paper, the fabricated system based on temperature reduction method (TRM), procedure of crystal growth, and characterization of the grown crystals are discussed.

\section{Crystal growth system}

The main system consists of crystallizer and water bath. Crystallizer is a Pyrex cylinder 6000cc in volume inserted in water bath to avoid of temperature loss. Water bath is a cylinder made of hard polyethylene $264 \mathrm{~cm}^{3}$ in volume and $68 \mathrm{~cm}$ in height, installed on a platform with adjustable legs, and having several ports for illumination, viewing and sensors. The whole system is placed inside a polycarbonate chamber $240 \times 140 \times 140 \mathrm{~cm}$ in sizes. Heating of system is provided by elements installed inside floor and walls of the chamber. Elements are connected to a sensor to ensure isolating of system and avoiding thermal interchange between bath and environment. Seed holder consists of two plates with four posts. A rod is passed through the middle of upper plate and connected to the rotation motor for continuously stirring the saturated solution. All the pieces of seed holder are made of Plexiglas. The z-cut seed crystal was glued on the lower plate of holder. The power of seed holder and stirrer was supplied by an electrometer.

The system is operated based on accelerated crystal rotation technique (ACRT) [10]. It could be rotated continuously with adjustable periods; respectively in clockwise, pause and then counterclockwise directions. As it was shown in Fig. 1 two Jumo PIDs with Pt100 probes have been used for temperature control of the main chamber and water bath.

\section{Experiment}

The KDP crystals are often grown from seeds cut perpendicular to the c-axis, means (001) seeds. A sample of seed with a few millimeters in thickness was polished with KDP solution and emery paper. The temperature of saturated solution was kept above the desired temperature for the start of ramping. In fact overheating was done to ensure of solving all the KDP salt molecules in the solution. The temperature of bath was set between 60$70^{\circ} \mathrm{C}$ to avoid of evaporation and wearing out of system. Seed was introduced in solution at $48^{\circ} \mathrm{C}$ and the run was initiated with a rate of $0.01{ }^{\circ} \mathrm{C} / \mathrm{h}$. To avoid of cracking due to unexpected heating, seed must be at the same temperature as the saturated solution. However at the early hours of introducing the seed, it may be start to melt, then regenerates its shape and during next hours the growth process will be started. This procedure has taken a time about $24 \mathrm{~h}$. Clarity of seed and appearance of pyramidal faces at the top of it is an evidence for the beginning of the growth process and regeneration of seed. 
Table. The summary of KDP crystal growth experiments.

\begin{tabular}{|c|c|c|c|c|c|c|}
\hline 声 & 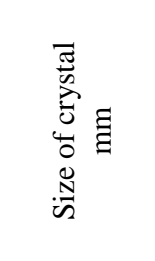 & 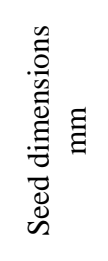 & 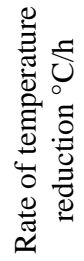 & 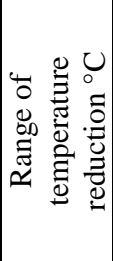 & 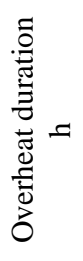 & 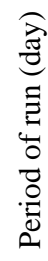 \\
\hline 1 & $20 \times 30 \times 55$ & $5 \times 7 \times 12$ & 0.01 & $59-52$ & 48 & 28 \\
\hline 2 & $23 \times 20 \times 84$ & $10 \times 7 \times 7$ & 0.01 & $50-40$ & 48 & 42 \\
\hline 3 & $37 \times 41 \times 130$ & $10 \times 8 \times 7$ & 0.02 & $70-23$ & 72 & 98 \\
\hline 4 & $160 \times 40 \times 38$ & $9 \times 8 \times 8$ & 0.01 & $51-32$ & 96 & 90 \\
\hline
\end{tabular}

After introducing seed in the solution, temperature should be decreased by a scheduled program to maintain the stability of supersaturation during the growth procedure. In the run 2, Table, $1850 \mathrm{~g}$ powder of KDP (Merck Company) was solved in $5500 \mathrm{~cm}^{3}$ distilled water in a Pyrex jar. The saturated solution was stirred by a magneto stirrer. Filtration as a necessary step was accomplished during the solution was poured in the crystallizer to ensure of solving all the macromolecules and removing insoluble particles. Then solution had been overheated at $55^{\circ} \mathrm{C}$ for $48 \mathrm{~h}$ to ensure of solving powder completely. The results of the growth experiments are summarized in Table. The average growth rate was about $1.8 \mathrm{~mm} /$ day. The grown crystals shown in Fig. 2 are examples of growth experiments.

\section{Optical transmission studies}

The main application of KDP single crystals is in optical devices, so the optical transmission range was detected for them. The KDP single crystals grown show about $86 \%$ transmission in the visible region as indicated by the curve in Fig. 3. This figure provides the transmission spectrum of the polished (001) plane for the 200-2500 nm wavelength. The spectrum has been obtained by Cary 17DX Spectrophotometer and immediately after polishing.

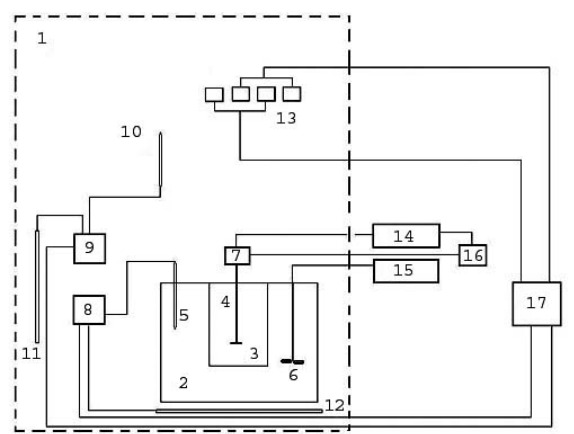

Fig. 1. Schematic diagram of crystallizer unit: 1 - main chamber, 2 - water bath, 3 - crystallizer, 4 - seed holder, 5 water bath thermo sensor, 6 - stirrer, 7 - electromotor, 8 - bath thermocontroller, 9 - chamber thermocontroller, 10 - chamber thermosensor, 11 - chamber heater, 12 - crystallizer heater, 13 - ventilators to keep uniformity of chamber weather, 14 electromotor power supply, 15 - stirrer power supply, 16 ACRT ciruit, 17 - AC power $(50 \mathrm{~Hz}, 220 \mathrm{~V})$.

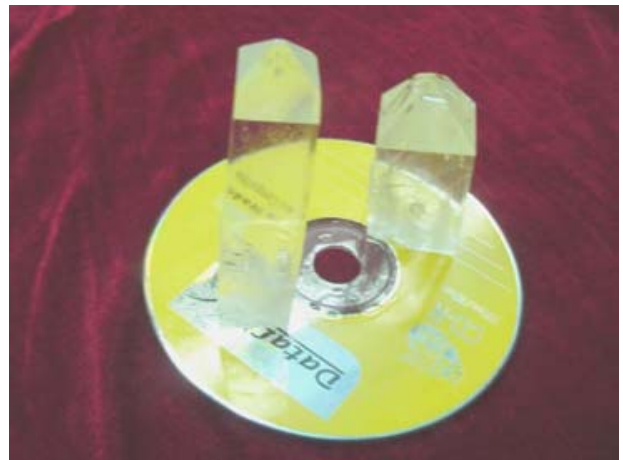

Fig. 2. Photograph of the KDP crystals grown in run 2, 3.

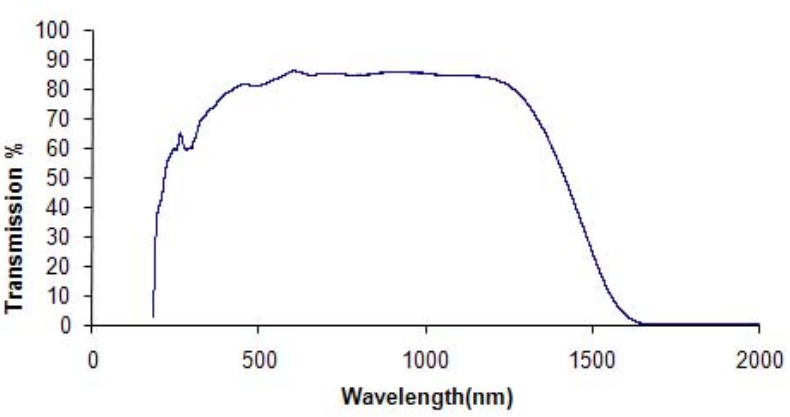

Fig. 3. Transmission spectrum of the (001) face a typical crystal grown in the UV to IR region.

\section{X-ray diffraction studies}

The well grinded powder of a grown KDP crystal was used to identify the crystal phase and structure. X-ray powder diffraction patterns of the grown crystals are consistent with the pure KDP crystal [11]. The analysis performed with Philips Pw1130/90 analyzer using a tube voltage and current of $40 \mathrm{kV}$ and $100 \mathrm{~mA}$, respectively. The recorded spectrum is shown in Fig. 4 is coincidence with JCPDS card No. 35-0807.

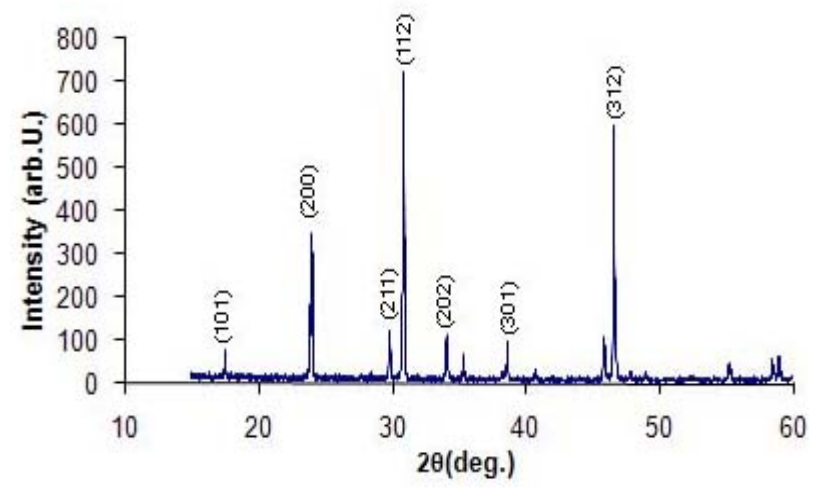

Fig. 4. X-ray powder diffraction pattern for KDP. 


\section{Study of laser damage threshold}

Study of damage laser threshold is an important parameter in qualification of nonlinear crystals [12]. In our experiment measurements were performed according to international standard ISO 11254 using a Nd:YAG laser vertically irradiated on the surface of sample with wavelength of $1064 \mathrm{~nm}$ in $\mathrm{TEM}_{00}$ transverse mode by linear polarization. Pulse duration and repetition rate was $10-12 \mathrm{~ns}$ and $1 \mathrm{~Hz}$, respectively. Damage definition was detected by an optical microscope with magnification 100. Damage threshold of the KDP crystal was $22.5 \mathrm{~J} / \mathrm{cm}^{2}$.

\section{Microhardeness test}

Microhardeness is a good testing to determine the firmness degree of matters. This test was performed on a crystal KDP of size $13 \times 11 \times 7 \mathrm{~mm}$. Measurements were carried on by Leitz MM6 microhardeness tester fixed to a Vickers diamond pyramidal indenter attached to a microscope. Test was made on the 100 face of crystal with $25 \mathrm{~g}$ load for $10 \mathrm{~s}$. $206 \mathrm{Hv}$

The hardness of KDP crystal was measured

\section{Etching studies}

Etching method is a very common and inexpensive technique to reveal dislocations and lattice inhomogenities of the crystals [13]. The KDP specimen plates were cut in two orientations and then polished on the natural suede clothed metal disk by a supersaturating solution of KDP as a suitable solvent in the room temperature [14]. One slice of (101) faces was dipped in distilled water for $3 \mathrm{~s}$, at room temperature, and then it was dried by the air cool blow. The formed etch pits on the surface of sample appeared as concentrated triangles (Fig. 5).

As Sangwal et al. [15] reported different etchant solutions have been examined to study of etching characteristics of (100) face of KDP crystal: deionized water, a mixture of two solvents. So the sample was dipped respectively in

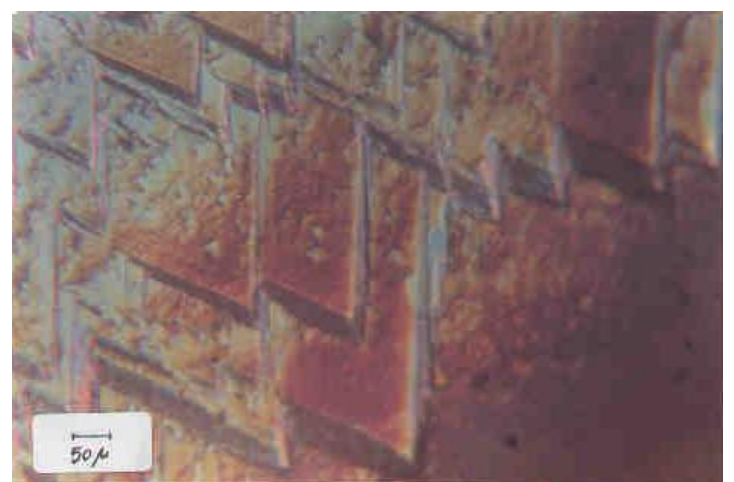

Fig. 5. Triangle etch pits patterns formed on the (101) face of KDP by pure water.

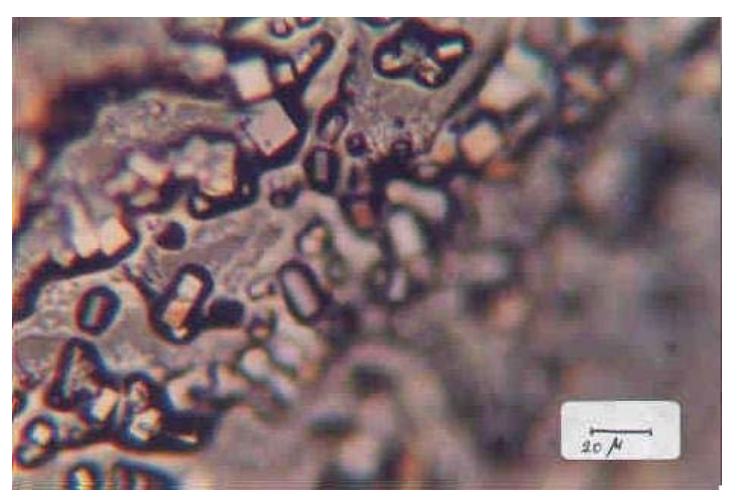

Fig. 6. Rectangular etch pit patterns formed on (100) surface of KDP by saturated acetic acid with KI.

1 part $\mathrm{H}_{2} \mathrm{O}+19$ part $\mathrm{CH}_{3} \mathrm{OH}$ for 50 min (without any result);

1 part $\mathrm{H}_{2} \mathrm{O}+5$ part $\mathrm{CH}_{3} \mathrm{COCH}_{3}$ for 45 min (without any result);

$10 \mathrm{ml}$ sulphuric acid (normal) $+100 \mathrm{ml}$ acetic acid for $60 \mathrm{~s}$ (without any result);

and acetic acid saturated with KI salt for $90 \mathrm{~s}$. Then it was dried by a hot air current. The produced features are shown in Fig. 6. The rectangular shaped pits formed by the etchant were very distinct. Distribution of clear parallelograms on the whole of surface is considerable. Orientation of the formed etches pits on the (100) face is different from each other. Etching experiments showed the appearance shape of the formed etch pits on the (100) and (101) by using different etchants would be the same. It can be concluded the revealed pits are due to linear defects such as surface dislocations. Observation and photography of the specimens were carried out by an optical microscope system, Reichert Metavar which equipped with an automatic camera, Wild MP551.

\section{Conclusion}

The above research was shown KDP crystals with desired dimensions could be grown by the fabricated system based on temperature reduction method. The system which introduced here is simple in design and could be used for production of KDP crystals. We successfully grew crystals $160 \times 40 \times 38 \mathrm{~mm}$ in size that would be useful for the manufacture of elements of spatial-time response control and of frequency conversion in laser system. The quality of the grown crystals can be affected directly by the good selection of gradient and range of temperature reduction rate, during the period of growth. When growth process is started the capping region will be appeared. So it can not be expected the growing crystal follow a good growth pattern in the early stages of growth. Smallness of seed and its good quality will be very effective in growth procedure. Existing defects in seed can be inherited by crystal and it takes a long time to growing crystal can be correct its crystalline lattice. 
The crystallizer geometry can be affected on conducting growth procedure in linear or transversal form. In a crystallizer with a height of $h$ and diameter of $d$, the ratio of $d / h$ is approximately equals $1 / 2$; crystal considerably will be growing in the c-axis. Filtration of growth solution is a necessary step before starting of run. Experiments have been shown long time overheating will be reduced the amount of the formed nucleation in the bottom of crystallizer.

Microscopic observations of (101) and (100) faces after etching process show two types of features may be formed: triangles etch pits on pyramidal faces and parallelogram ones on prismatic faces which might be related to line defects like dislocations.

\section{Acknowledgements}

The authors are indebted to Dr. M. Maleki for his helpful advices concerning the reviewing of this article, they also wish to thank V. Faghihi on aspects of the laser damage threshold experiment, Z. Dorriz for providing spectral curve, N. Afshari for providing XRD curve, $\mathrm{H}$. Kalbasi for making microhardeness testing, and workshop personnel for their technical assistance.

\section{References}

1. T. Sasaki, A. Yokotani, Growth of large KDP crystals for laser fusion experiments // J. Cryst. Growth 99, p. 820-826 (1990).

2. F.T. Arecchi, F.O. Schuls-Dubion, Laser Handbook, vol. 3. Amsterdam, p. 449 (1972).

3. F.T. Arecchi, F.O. Schuls-Dubion, Laser Handbook, vol. 1. Amsterdam, p. 881 (1972).

4. R.A. Negres, S.O. Kucheyev, P. De Mange, C. Bostedt, T. Van Buuren, A.J. Nelson, S.G. Demos, Decomposition of $\mathrm{KH}_{2} \mathrm{PO}_{4}$ crystals during laser-induced breakdown // Appl. Phys. Lett. 86, 171107 (2005).

5. N.P. Zaitseva, J. Atheron, R. Rozsa, L. Carman, I. Smolsky, M. Runkel, R. Ryon, L. James, Design and benefits of continuous filtration in rapid growth of large KDP and DKDP crystals // J. Cryst. Growth 197, p. 911-920 (1999).

6. G.M. Loiacono, J.J. Zola, G. Kostecky, Growth of $\mathrm{KH}_{2} \mathrm{PO}_{4}$ crystals at constant temperature and supersaturation // J. Cryst. Growth 62, p. 545-556 (1983).

7. A. Yokotani, H. Koide, T. Sasaki, T. Yamanaka, C. Yamanaka, Fast growth of KDP single crystals by electro dialysis method // J. Cryst. Growth 67, p. 627-632 (1984).

8. W. Shui, P. Bennema, W.H. Van Der Linden, J. Boshaar, J.W.M. Van Kessel, H. Klapper, Growth phenomena of KDP crystals in relation to the internal structure // J. Cryst. Growth 83, p. 471480 (1987).

9. G.M. Loiacono, J.J. Zola, G. Kostecky, The tapper effect in $\mathrm{KH}_{2} \mathrm{PO}_{4}$ type crystals // J. Cryst. Growth 58, p. 495-499 (1982).

10. V.K. Dixit, B.V. Rodrigues, H.L. Bhat, Experimental setup for rapid crystallization using favoured chemical potential and hydrodynamic conditions // Bull. Matter. Sci. 24, No. 5, p. 455-459 (2001).

11. D. Xu, D. Xue, Chemical bond analysis of the crystal growth of KDP and ADP// J. Cryst. Growth 286, p. 108-113 (2006).

12. C.W. Carr, M.D. Feit, A.M. Rubenchik, J.B. Trenholme, M.L. Spaeth, A summary of recent damage - intiation experiments on KDP crystals // Proc. SPIE 5991, p. 1Q-1_1Q-8 (Feb. 2006).

13. G. Ravi, A.S. Haja Hameed, P. Ramasamy, Effect of temperature and deuterium on the growth of deuterated potassium dihydrogen phosphate (DKDP) single crystals // J. Cryst. Growth 207, p. 319-324(1999).

14. W.J.P. Van Enckevort and W.H. Van Der Linden, On the relation between etch pits or growth hillocks and dislocations on the (111) faces of potassium aluminum alum // J. Cryst. Growth 47, p. 196-202 (1979).

15. K. Sangwal, M. Szurgut, J. Karniewicz, W. Kolasinski, On the selective etching of KDP crystals // J. Cryst. Growth 58, p. 261-266 (1982). 